\title{
Acute pain after total hip arthroplasty does not predict the development of chronic postsurgical pain 6 months later
}

\author{
Hance Clarke $\cdot$ Joseph Kay $\cdot$ \\ Nicholas Mitsakakis • Joel Katz
}

\begin{abstract}
Purpose Much remains unknown about the relationship between acute postoperative pain and the development of pathologic chronic postsurgical pain (CPSP). The purpose of this project was to identify the extent to which maximum pain scores on movement over the first two days after total hip arthroplasty predicted the presence of chronic pain 6 months later after controlling for potentially important covariates.

Methods The sample comprised 82 of 114 patients who participated in a double-blinded randomized controlled trial in which all patients received acetaminophen $1 \mathrm{~g}$ p.o., celecoxib $400 \mathrm{mg}$ p.o., and dexamethasone $8 \mathrm{mg}$ i.v., $1-2 \mathrm{~h}$ preoperatively. In addition, patients received gabapentin (GBP) $600 \mathrm{mg}$ (G2) or placebo (G1 and G3) $2 \mathrm{~h}$ prior to surgery [G1: placebo/placebo $(n=38) ; \mathrm{G} 2$ : GBP/ placebo $(n=38)$; G3: placebo/GBP $(n=38)$ ]. In the PACU, patients received gabapentin $600 \mathrm{mg}$ (G3) or placebo (G1 and G2). Follow-up data from the 82 patients
\end{abstract}

H. Clarke $(\square)$ - N. Mitsakakis - J. Katz

Department of Anesthesia and Pain Management,

Toronto General Hospital, Acute Pain Research Unit,

200 Elizabeth Street, Eaton North 3EB 317, Toronto,

ON M5G 2C4, Canada

e-mail: hance.clarke@utoronto.ca

H. Clarke - J. Kay - J. Katz

Holland Orthopedic and Arthritic Centre,

Sunnybrook Health Sciences Centre, Toronto, ON, Canada

J. Katz

Department of Psychology and School of Kinesiology and

Health Science, York University, Toronto, ON, Canada

H. Clarke - J. Kay

Department of Anesthesia, University of Toronto,

Toronto, ON, Canada who were contacted by telephone 6 months postsurgery were used for the current study.

Results Maximal movement-evoked pain intensity over the first two postoperative days $(P=0.38)$ failed to predict the presence of CPSP 6 months later after controlling for age $(P=0.09)$, treatment group $(P=0.91)$, and cumulative morphine consumption $(P=0.8)$ (multivariate logistic regression likelihood ratio test against the intercept only model $P=0.59$ ).

Conclusion Neither maximum movement-evoked acute pain, nor any other factor measured, predicted the presence of CPSP at 6 months. Further research is needed to identify risk factors for CPSP after total hip arthroplasty.

Keywords Acute pain - Chronic postsurgical pain . Total hip arthroplasty

\section{Introduction}

Chronic postsurgical pain (CPSP) has been defined as pathologic pain that persists for longer than 2 months postsurgery [1]. Neuropathic pain (pain arising as a direct consequence of a lesion or disease affecting the somatosensory system) [2] has been implicated as a major contributor to the development of neuropathic pain $[3,4]$. A prospective longitudinal study examining patients that experienced intense neuropathic pain in the acute hospital period found that $56 \%$ of these patients reported chronic neuropathic pain 1 year postdischarge [5].

One year after total hip arthroplasty, the incidence of CPSP has been reported to be as high as 30\% [6]. Results from a Danish nationwide study found that $12.1 \%$ of patients after hip arthroplasty were significantly impaired (12-18 months later) in their daily activities by CPSP [7]. 
After most surgical procedures, the majority of patients recover uneventfully. It is evident that some surgical procedures are associated with a higher incidence of CPSP [6]. CPSP is becoming a widely recognized societal and economic problem. Currently, up to $25 \%$ of all patients referred to chronic pain treatment centres suffer with CPSP [8].

The risk factors associated with the development of CPSP are currently under investigation [4]. The most consistent finding in the literature thus far has been that the presence of current pain (either preoperative or acute postsurgical pain) predicts future pain [4, 9-12]. Other factors such as younger age $[13,14]$, female gender $[9,15]$, the presence of anxiety $[9,16]$, pain catastrophizing [17], and other psychological variables such as emotional numbing [18] have been shown to predict the development of postsurgical pain after a variety of surgical procedures [4]. We must continue efforts to determine which aspects of the perioperative pain experience are predictive of the transition to pain chronicity: qualities specific to the pain itself (e.g. intensity, quality, duration), or qualities inherent to the individuals that are reporting the pain (e.g. response bias, psychological vulnerability, genetic predisposition) [4]?

In previous work, we found that regardless of the timing and whether or not gabapentin (an $\alpha 2 \delta$ voltage-dependent calcium channel blocker) was administered (i.e. before surgery/after surgery/or not at all), differences were not found in the acute perioperative period with respect to opioid consumption, pain at rest, or movement-evoked pain after total hip arthroplasty [19]. All patients also received a clinically relevant, preventive, multimodal regimen of acetaminophen, celecoxib (Cox-2 selective inhibitor), and spinal anesthesia [19]. The aim of the current paper was to test whether maximal movement-evoked acute pain scores would predict the development of CPSP in the sample of patients who had undergone total hip arthroplasty.

Several trials have demonstrated that the intensity of acute postoperative pain predicts the transition to CPSP [11, 20-22]. In the present paper, we selected maximal movement pain as the primary pain outcome measure because movement pain scores are typically higher than pain scores at rest. As well, movement-evoked pain is more difficult to treat than rest pain [23], and it is an important marker of postoperative physical activity such as the ability to bear weight during ambulation [24]. Secondary outcome measures included preoperative anxiety, morphine consumption, age and gender, and their relationship to the development of CPSP.

\section{Materials and methods}

This study was approved by the Sunnybrook Health Sciences Centre Research Ethics Board. All patients gave informed, written consent to participate. Eligible patients were between the ages of 18 and 75 years, had an ASA physical status score of I, II, or III, and had undergone total hip arthroplasty. Patients were not eligible if they met any of the following exclusion criteria: a known allergy to any of the medications being used; a history of drug or alcohol abuse; a history of being on chronic pain medications (i.e. slow-release preparations of opioids); rheumatoid arthritis; a psychiatric disorder; a history of diabetes with impaired renal function; a body mass index of greater than 45; or an unability, or unwillingness, to use patient-controlled analgesia (PCA).

Data for the present study were collected as part of a prospective research project examining the effects of adding a single dose of GBP to a multimodal anesthetic regimen with spinal anesthesia [19]. Patients were recruited at their preoperative assessment visit approximately 1-2 weeks in advance of their surgery. At that time, the study procedures were explained to the patients, including the use of the PCA pump and the visual analogue pain scale (VAS) (a $10 \mathrm{~cm}$ scale with endpoints labeled "no pain" and "worst pain possible").

The above sample was comprised of 114 patients who participated in a double-blind, randomized, controlled trial in which all participants had received acetaminophen $1 \mathrm{~g}$ p.o. and celecoxib $400 \mathrm{mg}$ p.o. $2 \mathrm{~h}$ preoperatively [19]. The focus of the study was to examine the effects of GBP on anxiety, postoperative pain and opioid consumption. Patients were randomly assigned to one of three treatment groups (before/after anesthesia): Group 1: placebo/placebo; Group 2: GBP/Placebo; Group 3: placebo/GBP. Group 2 received GBP $600 \mathrm{mg}$ p.o. $2 \mathrm{~h}$ prior to surgery; the other groups received a placebo capsule that looked identical to the GBP capsule. Group 3 received GBP $600 \mathrm{mg}$ p.o. upon arrival at the postanesthetic care unit; the other groups received a placebo capsule that looked identical to the GBP capsule. All patients received an i.v. PCA pain pump and opioid consumption was recorded for the first $48 \mathrm{~h}$ after surgery. Also, patients were asked to rate their pain intensity using the VAS described earlier: patient pain scores at rest and movement-evoked pain scores were recorded every $4 \mathrm{~h}$ up to $48 \mathrm{~h}$ after surgery [19].

For the present study, additional approval by the Sunnybrook Health Sciences Centre Research Ethics Board was obtained. Patients were contacted and verbally reconsented to participation by telephone 6 months after surgery. A maximum of three calls were made and a voice message was left on the third call. Patients were considered lost to follow-up if they could not be reached and did not return the call. Patients were administered the following three questionnaires: a follow-up Hip Arthroplasty Pain Questionnaire, The Neuropathic Pain Scale [25], and The Hospital Anxiety and Depression Scale [26]. Pain intensity 
was measured with a numeric rating scale (NRS). The NRS consists of a series of numbers ranging from 0 to 10 with endpoints representing the most extreme pain experiences $(0=$ no pain, $10=$ worst possible pain). The NRS has been shown to have good reliability and validity and is sensitive to change following pharmacological intervention [27].

\section{Statistical analysis}

Demographic and clinical variables were compared between patients with and without pain at 6 months using the Mann-Whitney $U$ test (for continuous data) and Fisher's exact test (for categorical data). A multivariate logistic regression model predicting the presence or absence of pain at 6 months from age, treatment group, cumulative morphine consumption ( $48 \mathrm{~h}$ postoperatively) and maximal movement-evoked pain intensity over the first $48 \mathrm{~h}$ after surgery was fitted to the data. Thus, the regression model examined the extent to which acute maximal movement evoked pain in the first $48 \mathrm{~h}$ after surgery predicted the development of CPSP 6 months later after controlling for relevant clinical and demographic factors.

\section{Results}

Figure 1 depicts the recruitment and retention of study patients. Overall 439 patients were screened for recruitment into the trial. Of these, $121 \mathrm{did}$ not meet the inclusion criteria ( 34 were older than 75 years of age, 29 had diabetes and/or an elevated creatinine, 16 declared an allergy to one of the study medications, 12 had a history of being on chronic pain medications, 11 presented with a psychiatric disorder, 9 had a BMI $>45,5$ were not proficient in English, and 5 had rheumatoid arthritis).

Incidence of chronic pain

One hundred and twenty-six patients were recruited into the study. One hundred and fourteen patients completed the in-hospital protocol. Six months after surgery, 82 (71.9\%; 51 male, 31 female) of the 114 patients who completed the study were interviewed. Between the in-hospital intervention and 6-month follow-up, 20 patients were lost to follow-up (unable to be contacted) and 12 refused to be interviewed. Of the 82 patients that were interviewed at 6 months, $31(37.5 \%)$ patients reported chronic pain related to their hip arthroplasty (i.e. $27 \%$ of the total number of patients that completed the in-hospital protocol (31/114).

Predictors of the development of chronic pain

Table 1 shows the primary and secondary outcome measures for patients that reported and did not report pain 6 months after surgery. The results of the data analyses did not show evidence of a significant association between the presence or absence of CPSP at 6 months and age
Fig. 1 Patient recruitment and patient flow

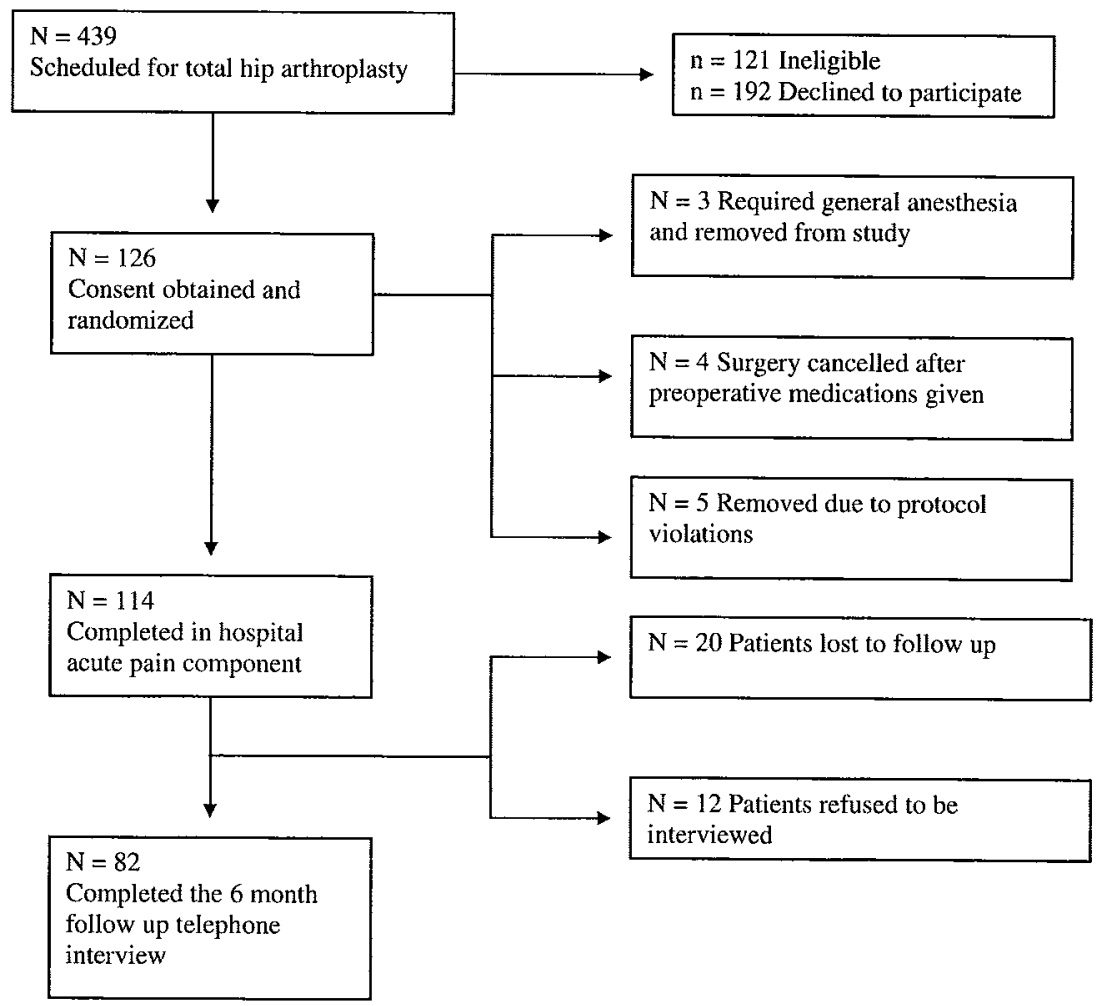


Table 1 Primary and secondary outcome measures shown for patients that reported and did not report pain 6 months after surgery

\begin{tabular}{llll}
\hline Factor & $\begin{array}{l}\text { Patients with chronic } \\
\text { pain 6 months after } \\
\text { surgery }(n=31)\end{array}$ & $\begin{array}{l}\text { Patients that reported } \\
\text { no pain 6 months post } \\
\text { surgery }(n=51)\end{array}$ & $P$ value \\
\hline $\begin{array}{l}\text { Maximal pain intensity with movement } \\
\text { after surgery (VAS 0-100) }\end{array}$ & $60.7 \pm 23.2$ & $58.4 \pm 19.3$ & 0.38 \\
$\begin{array}{l}\text { Cumulative morphine consumption } \\
\quad \text { at 48 h after surgery }\end{array}$ & $49.4 \pm 26.2$ & $46.9 \pm 30.3$ & 0.68 \\
$\begin{array}{l}\text { Preoperative anxiety (VAS 0-100) } \\
\text { Age (years) }\end{array}$ & $23.3 \pm 20.3$ & $23.7 \pm 21.1$ & 0.96 \\
Gender (M/F) & $59.0 \pm 8.8$ & $61.6 \pm 9.3$ & 0.17 \\
Group randomization (placebo/pre-/post-) & $17 / 14$ & $34 / 17$ & 0.35 \\
\hline & $10 / 12 / 9$ & $18 / 16 / 17$ & 0.85 \\
\hline
\end{tabular}

Table 2 Multivariate logistic regression model predicting the development of chronic postsurgical pain 6 months after total hip arthroplasty

Likelihood ratio test against intercept-only model, $P=0.59$. Significance not found with above model

\begin{tabular}{lclll}
\hline $\begin{array}{l}\text { Covariates of the model predicting } \\
\text { the incidence of chronic postsurgical pain }\end{array}$ & Beta & $\begin{array}{l}\text { Standard } \\
\text { error }\end{array}$ & Chi-square & $P$ value \\
\hline Intercept & 1.43 & 1.87 & 0.59 & 0.44 \\
Age & -0.046 & 0.027 & 2.77 & 0.1 \\
Group randomization: Group 1 & 0.1 & 0.6 & 0.028 & 0.87 \\
Group randomization: Group 2 & 0.25 & 0.6 & 0.168 & 0.68 \\
Cumulative morphine consumption & -0.002 & 0.009 & 0.06 & 0.81 \\
Maximal pain intensity with movement & 0.012 & 0.012 & 0.88 & 0.35 \\
\hline
\end{tabular}

( $P=0.17)$, gender $(P=0.35)$, group randomization $(P=0.85)$, cumulative morphine consumption $(P=0.68)$, preoperative anxiety $(P=0.96)$ or acute maximal movement-evoked pain after surgery $(P=0.38)$. Using maximal-evoked pain intensity $(P=0.38)$ as the outcome of interest, the multivariate logistic regression model using age $(P=0.09)$, group randomization $(P=0.91)$, and cumulative morphine consumption $(P=0.8)$ as covariates also failed to show a significant relationship with the presence of CPSP after total hip arthroplasty (likelihood ratio test against the intercept only model $P=0.59$ ) (Table 2).

\section{Discussion}

The results of the present prospective study demonstrate that $37.5 \%$ (31/82) of patients report CPSP 6 months after total hip arthroplasty. None of the following factors predicted the development of CPSP 6 months after surgery: maximal-movement evoked pain intensity after surgery cumulative morphine consumption at $48 \mathrm{~h}$ after surgery, preoperative anxiety, age, gender, or treatment with GBP (Table 1). Consistent with these findings, the multiple logistic regression model (Table 2) failed to show a significant association between maximal acute pain on movement and the development of CPSP 6 months after surgery.
The average daily pain intensity scores at 6 months were $<4 / 10$ (i.e. mild to moderate in magnitude) and were accompanied by little disruption in daily functioning [19]. Likewise, in the immediate postoperative period $(\sim 48 \mathrm{~h})$, pain at rest and with movement were well managed (mean $<4 / 10$ ) throughout [19]. Given the finding that intense acute pain predicts the development of CPSP [4, 9-12], the mild to moderate intensity of the maximal movement evoked pain intensity (Table 1) in the present study may have contributed to the lack of an association between the intensity of acute postoperative pain and the long-term development of CPSP.

The mild to moderate pain experienced postoperatively is likely due to the aggressive multimodal perioperative regimen routinely used at our institution [i.e. opioids, acetaminophen, nonsteroidal anti-inflammatories (COX-2 inhibitor), and gabapentinoids ( $\alpha 2 \delta$ calcium channel blocker)]. Other studies that reported associations between acute postoperative pain and the development of CPSP syndromes had cohorts of patients that reported significantly higher acute pain scores after limb arthroplasty [28] and postmastectomy [22]. Katz and colleagues [11] demonstrated an association with moderate to severe acute postoperative pain and the development of CPSP after posterolateral thoracotomy. This finding is consistent with recent results reported by Gottschalk and Ochroch [20]. More data are needed to determine whether similar multimodal pain regimens which tend to be effective in 
reducing acute postoperative pain intensity also reduce the correlation between acute pain intensity and pain chronicity.

The present study also examined the relationship between preoperative anxiety scores and the development of CPSP. Previous studies have demonstrated that high preoperative anxiety is associated with increased acute postoperative pain [29], postoperative analgesic consumption [29], and the development of CPSP [16, 30, 31]. Our results failed to demonstrate such an association. The baseline preoperative anxiety levels were quite low in our cohort, with mean scores of less than $3 / 10$ preoperatively in both groups (Table 1). These very low baseline anxiety scores may have created a floor effect in which clinically meaningful reductions in anxiety were not possible. Further examination of the preoperative anxiolytic effects of GBP should be undertaken using patients with higher preoperative anxiety scores.

Notwithstanding the negative results of the present study, pain is influenced by a host of psychological factors, and based on the Initiative on Methods, Measurement, and Pain Assessment in Clinical Trials (IMMPACT) consensus guidelines, it has been recommended that psychological variables should be examined in pain-related clinical trials [32]. Psychological variables such as preoperative state anxiety [16], an introverted personality [33], high catastrophizing, greater social support, and solicitous responding in the week after amputation [34, 35], higher concurrent emotional numbing scores at 6 and 12 months [18], greater preoperative catastrophizing [30,31], fear of surgery [21], and "psychic vulnerability" [36], a construct similar to neuroticism [37] have all been associated with the development of CPSP [4]. Further research is needed with respect to determining the extent to which these risk factors predict the development of CPSP after total hip arthroplasty.

Factors such as age [9, 22], female gender [22], and opioid consumption have been identified as predictors of the transition to CPSP [4]. Our results failed to demonstrate such associations (Table 1). In comparison with other studies, the mean opioid consumption after THA in both groups was quite low [38, 39]. It is well established that the intensity of postoperative pain is correlated with the amount of opioid medication consumed by the patient [38]. The relatively infrequent use of opioid analgesics in our cohort is likely attributable to the adjunctive medications given, which decreased the pain intensity. Studies have reported that female gender [9] and younger age $[9,40]$ predicted intense acute postoperative pain, and nationwide surveys consistently find that the incidence of chronic neuropathic pain is significantly higher in women than men [41-43]. Several smaller studies of CPSP have also identified younger age as a risk factor for the transition from acute pain to pain chronicity $[14,22]$. The sample of patients enrolled in the present study was quite homogeneous with respect to age and gender and neither predicted chronic pain 6 months after total hip arthroplasty [19].

There are several limitations to the present study. First, preoperative baseline variables were not recorded with respect to patients' preoperative pain. Previous studies have demonstrated that one of the most consistent patientrelated predictors of acute and CPSP is preoperative pain $[4,10,37]$. Furthermore, $71 \%(82 / 114)$ of patients were reached for follow-up 6 months after surgery, raising the possibility that our results may have been biased by patients with chronic pain (i.e., if the remaining $29 \%$ did not have pain). However in the event that the entire cohort had responded, a 27\% (31/114) incidence of chronic pain would have been higher than expected given the very good perioperative pain control. The aggressive multimodal analgesic regimen used in the present study is unique with respect to the examination of CPSP. When compared to other postsurgical cohorts used to report the incidence of CPSP, patients in our study were exposed to various analgesic agents. Table 1 demonstrates that the maximal pain intensity typically experienced by our patient cohort tended to be of a moderate nature, so the heterogeneous cocktail of medications given to our patients could also be viewed as a limitation to the current study.

Our results continue to highlight the complexity of attempting to determine potential risk factors responsible for the transition of acute pain to a CPSP syndrome. The transition to chronicity is a developmental process that likely involves biological, psychological, and socioenvironmental factors [4]. We were unable to identify any such risk factors associated with this transition. Whether CPSP develops based on the intensity of acute pain after the surgical experience, damage to neuronal structures that leads to long-lasting neuropathic pain, the patient's psychological vulnerabilities, or other factors remains to be elucidated. It is clear that well-designed trials are needed to determine the factors that predict the development of CPSP.

Acknowledgments This study was made possible through a grant from the Physicians' Services Incorporated. Many thanks to our study coordinator Beth Goudie RN, and to the Holland Orthopedic and Arthritic Centre's nursing staff and Pharmacy and Physiotherapy Departments for all of their hard work and support. Many thanks to Eileen Halket RN and the Acute Pain Research team at the Toronto General Hospital for their many hours of hard work. This work was performed in partial fulfillment of Hance Clarke's doctoral dissertation. Hance Clarke is supported by a Canadian Institute of Health Research Ph.D. Fellowship Award. Joel Katz is supported by a Canada Research Chair in Health Psychology. 


\section{References}

1. Macrae W, Davies H. Chronic postsurgical pain. In: Crombie IK, Linton S, Croft P, Von Knorff M, Leresche L, editors. The epidemiology of chronic pain. Washington: IASP Press; 1999. p. 125-42.

2. Loeser JD, Treede RD. The Kyoto protocol of IASP basic pain terminology. Pain. 2008;137:473-7.

3. Costigan M, Scholz J, Woolf CJ. Neuropathic pain: a maladaptive response of the nervous system to damage. Annu Rev Neurosci. 2009;32:1-32.

4. Katz J, Seltzer Z. Transition from acute to chronic postsurgical pain: risk factors and protective factors. Expert Rev Neurother. 2009;9:723-44.

5. Hayes C, Browne S, Lantry G, Burstal R. Neuropathic pain in the acute pain service: a prospective study. Acute Pain. 2002;4:45-8.

6. Goldstein DH, Ellis J, Brown R, Wilson R, Penning J, Chisom K, VanDenKerkhof $E$. Recommendations for improved acute pain services: Canadian collaborative acute pain initiative. Pain Res Manag. 2004;9:123-30.

7. Nikolajsen L, Brandsborg B, Lucht U, Jensen TS, Kehlet H. Chronic pain following total hip arthroplasty: a nationwide questionnaire study. Acta Anaesthesiol Scand. 2006;50:495-500.

8. Gray P. Acute neuropathic pain: diagnosis and treatment. Curr Opin Anaesthesiol. 2008;21:590-5.

9. Kalkman CJ, Visser K, Moen J, Bonsel GJ, Grobbee DE, Moons KG. Preoperative prediction of severe postoperative pain. Pain. 2003;105:415-23.

10. Katz J. Pain begets pain-predictors of long-term phantom limb pain and post-thoracotomy pain. Pain Forum. 1997;6:140-4.

11. Katz J, Jackson M, Kavanagh BP, Sandler AN. Acute pain after thoracic surgery predicts long-term post-thoracotomy pain. Clin $\mathbf{J}$ Pain. 1996;12:50-5.

12. Kehlet H, Jensen TS, Woolf CJ. Persistent postsurgical pain: risk factors and prevention. Lancet. 2006;367:1618-25.

13. Poobalan AS, Bruce J, King PM, Chambers WA, Krukowski ZH, Smith WC. Chronic pain and quality of life following open inguinal hernia repair. Br J Surg. 2001;88:1122-6.

14. Maguire MF, Ravenscroft A, Beggs D, Duffy JP. A questionnaire study investigating the prevalence of the neuropathic component of chronic pain after thoracic surgery. Eur J Cardiothorac Surg. 2006;29:800-5.

15. Thomas T, Robinson C, Champion D, McKell M, Pell M. Prediction and assessment of the severity of post-operative pain and of satisfaction with management. Pain. 1998;75:177-85.

16. Harden RN, Bruehl S, Stanos S, Brander V, Chung OY, Saltz S, Adams A, Stulberg SD. Prospective examination of pain-related and psychological predictors of CRPS-like phenomena following total knee arthroplasty: a preliminary study. Pain. 2003;106:393400 .

17. Sommer M, Geurts JW, Stessel B, Kessels AG, Peters ML, Patijn $J$, van Kleef M, Kremer B, Marcus MA. Prevalence and predictors of postoperative pain after ear, nose, and throat surgery. Arch Otolaryngol Head Neck Surg. 2009;135:124-30.

18. Katz J, Gordon A, McCrae K, Halket E. Emotional numbing and pain intensity predict the development of pain disability up to one year after lateral thoracotomy. Eur J Pain. 2009;13:870-8.

19. Clarke H, Pereira S, Kennedy D, Andrion J, Mitsakakis N, Gollish J, Katz J, Kay J. Adding gabapentin to a multimodal regimen does not reduce acute pain, opioid consumption or chronic pain after total hip arthroplasty. Acta Anaesthesiol Scand. 2009;53:1073-83.

20. Gottschalk A, Ochroch EA. Clinical and demographic characteristics of patients with chronic pain after major thoracotomy. Clin J Pain. 2008;24:708-16.
21. Peters ML, Sommer M, de Rijke JM, Kessels F, Heineman E, Patijn J, Marcus MA, Vlaeyen JW, van Kleef M. Somatic and psychologic predictors of long-term unfavorable outcome after surgical intervention. Ann Surg. 2007;245:487-94.

22. Poleshuck EL, Katz J, Andrus CH, Hogan LA, Jung BF, Kulick DI, Dworkin RH. Risk factors for chronic pain following breast cancer surgery: a prospective study. J Pain. 2006;7:626-34.

23. Gilron I. Gabapentin and pregabalin for chronic neuropathic and early postsurgical pain: current evidence and future directions. Curr Opin Anaesthesiol. 2007;20:456-72.

24. Hurkmans HL, Bussmann JB, Benda E, Haisma JA, Verhaar JA, Stam HJ. Predictors of partial weight-bearing performance after total hip arthroplasty. J Rehabil Med. 2010;42:42-8.

25. Galer BS, Jensen MP. Development and preliminary validation of a pain measure specific to neuropathic pain: the neuropathic pain scale. Neurology. 1997;48:332-8.

26. Bjelland I, Dahl AA, Haug TT, Neckelmann D. The validity of the Hospital Anxiety and Depression Scale. An updated literature review. J Psychosom Res. 2002;52:69-77.

27. Katz J, Melzack R. Measurement of pain. Surg Clin N Am. 1999;79:231-52.

28. Hanley MA, Jensen MP, Smith DG, Ehde DM, Edwards WT, Robinson LR. Preamputation pain and acute pain predict chronic pain after lower extremity amputation. J Pain. 2007;8:102-9.

29. Katz J, Buis T, Cohen L. Locked out and still knocking: predictors of excessive demands for postoperative intravenous patient-controlled analgesia. Can J Anaesth. 2008;55:88-99.

30. Forsythe ME, Dunbar MJ, Hennigar AW, Sullivan MJ, Gross M. Prospective relation between catastrophizing and residual pain following knee arthroplasty: two-year follow-up. Pain Res Manag. 2008;13:335-41.

31. Sullivan M, Tanzer M, Stanish W, Fallaha M, Keefe FJ, Simmonds M, Dunbar M. Psychological determinants of problematic outcomes following total knee arthroplasty. Pain. 2009; 143:123-9.

32. Turk DC, Dworkin RH, Revicki D, Harding G, Burke LB, Cella D, Cleeland CS, Cowan P, Farrar JT, Hertz S, Max MB, Rappaport BA. Identifying important outcome domains for chronic pain clinical trials: an IMMPACT survey of people with pain. Pain. 2008;137:276-85.

33. Borly L, Anderson IB, Bardram L, Christensen E, Sehested A, Kehlet H, Matzen P, Rehfeld JF, Stage P, Toftdahl DB, Gernow A, Hojgaard L. Preoperative prediction model of outcome after cholecystectomy for symptomatic gallstones. Scand J Gastroenterol. 1999;34:1144-52.

34. Hanley MA, Jensen MP, Ehde DM, Hoffman AJ, Patterson DR, Robinson LR. Psychosocial predictors of long-term adjustment to lower-limb amputation and phantom limb pain. Disabil Rehabil. 2004;26:882-93.

35. Jensen MP, Ehde DM, Hoffman AJ, Patterson DR, Czerniecki JM, Robinson LR. Cognitions, coping and social environment predict adjustment to phantom limb pain. Pain. 2002;95:133-42.

36. Jorgensen T, Teglbjerg JS, Wille-Jorgensen P, Bille T, Thorvaldsen $\mathrm{P}$. Persisting pain after cholecystectomy. A prospective investigation. Scand J Gastroenterol. 1991;26:124-8.

37. Perkins FM, Kehlet $\mathrm{H}$. Chronic pain as an outcome of surgery. A review of predictive factors. Anesthesiology. 2000;93:112333.

38. Slappendel R, Weber EW, Bugter ML, Dirksen R. The intensity of preoperative pain is directly correlated with the amount of morphine needed for postoperative analgesia. Anesth Analg. 1999;88:146-8.

39. Giuffre M, Asci J, Amstein P, Wilkinson C. Postoperative joint replacement pain: description and opioid requirement. J Perianesth Nurs. 1991;6:239-45. 